\title{
ANÁLISE ERGONÔMICA COMPARATIVA ENTRE TRÊS METODOLOGIAS DE MODELAGEM DO VESTUÁRIO A PARTIR DAS HEURÍSTICAS DE NIELSEN
}

\section{COMPARATIVE ERGONOMIC ANALYSIS BETWEEN THREE FASHION PATTERN MAKING METHODOLOGIES FROM NIELSEN HEURISTICS}

\author{
Raquel Pizzolato de Oliveira1, Esp. \\ Bruna Marina Bischoff², Bela. \\ (1) Universidade do Estado de Santa Catarina \\ e-mail: raquelpizzolato@gmail.com \\ (2) Universidade do Estado de Santa Catarina \\ e-mail: brunamar@gmail.com
}

Palavras-chave: Usabilidade, modelagem do vestuário, heurísticas.

A análise ergonômica apresentada neste artigo consiste em comparar a usabilidade de três métodos distintos de modelagem do vestuário: Modelagem Plana, Moulage e Modelagem em CAD, a partir do conjunto das dez heurísticas definidas por Nielsen, a fim de identificar qual método atinge a meta desejada e satisfaz melhor as necessidades do usuário.

Key-words: Usability, fashion pattern making, heuristics.

The ergonomic analysis presented in this article compares the usability of three different methods of pattern making: Pattern Cutting, Drapping and Pattern with CAD, from the set of ten heuristics defined by Nielsen, in order to identify which method reaches the desired goal and better meets user needs.

\section{Introdução}

O alcance dos fatores humanos e ergonomia vai além da interação do humano-computador. Por isso, muitos métodos de usabilidade aplicam-se igualmente bem ao desenvolvimento de outros sistemas. De acordo com os autores Cybis, Betiol e Faust [2007] “[...] ergonomia está na origem da usabilidade, pois ela visa proporcionar eficácia e eficiência, além do bem-estar e saúde do usuário, por meio da adaptação do trabalho ao homem". [CYBIS, BETIOL, FAUST, 2007, p.15].

Para Nielsen [1993] a usabilidade está intimamente
Realização:

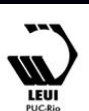

UNIVERSIDADE FEDERAL DE SANTA CATARINA 
$16^{\circ}$ USIHC - Congresso Internacional de Ergonomia e Usabilidade de Interfaces Humano Computador

relacionada à questão da aceitabilidade do sistema, que é basicamente a questão de se o sistema é suficientemente bom para satisfazer todas as necessidades e exigências dos usuários.

Neste estudo, o objetivo geral se constitui em avaliar três metodologias de modelagem do vestuário ergonomicamente e em relação à usabilidade, segundo as dez heurísticas de Nielsen [1993]. A avaliação heurística é feita olhando para uma interface e tentando chegar a uma opinião sobre o que é bom e ruim sobre a interface. Esta avaliação serve como uma inspeção sistemática da usabilidade do design da interface. Ou seja, seu objetivo é encontrar os problemas de usabilidade em um design de interface para que os usuários possam ser atendidos.

Para tanto, primeiramente se faz uma apresentação do conceito de modelagem como a etapa do processo de confecção do vestuário quando são interpretados os modelos criados planejando as formas a serem cortadas no tecido, para que após a montagem e costura das peças, o resultado final do produto seja compatível com as diretrizes iniciais. Em seguida, expõem-se as metodologias da modelagem plana, Moulage e modelagem em CAD, com suas principais características e particularidades.

Na sequência, é debatido o conceito de usabilidade quanto a seus princípios, propriedades e atributos, e se trata das técnicas de avaliação da ergonomia e suas classificações. As dez heurísticas de Nielsen [1993] são apresentadas de modo a possibilitar a análise heurística de usabilidade que se pretende realizar. Em seguida, constroem-se tabelas de classificação dos três tipos de metodologia de modelagem quanto a cada uma das dez heurísticas, e se realizam análises individuais.

Finalmente, traça-se um paralelo entre a análise das metodologias demonstrando que a modelagem plana atende a apenas quatro das dez heurísticas, a Moulage atende a seis e a modelagem em CAD a nove. Assim entende-se que a última é a metodologia que obteve melhor desempenho, mesmo sem ter sido de forma completa. Pode-se afirmar, a partir deste fato, que o ideal para que os requisitos ergonômicos e de usabilidade sejam atendidos de forma plena seja o uso conjunto de mais de uma metodologia de modelagem.

Juntamente as heurísticas demonstraram ser um conjunto de critérios eficaz para a identificação de desconformidades quanto à usabilidade destes métodos.

\section{Modelagem}

O processo da cadeia têxtil é composto por muitas etapas. A confecção vem a ser a última delas, pois sucede a produção da matéria prima, fiação, tecelagem, beneficiamento, entre outras, conforme demonstra Paiva [2010]. A confecção, por sua vez, também é realizada em fases complexas formando uma rede de atividades, como: planejamento da coleção, planejamento do processo produtivo, risco, corte, separação de componentes, costura, limpeza da peça, acabamento, embalagem, entre outras.

A modelagem é uma das tarefas da fase do planejamento da coleção. Segundo Araújo [1996], o trabalho do modelista têm início depois da criação do modelo pelo estilista, e sua função é "[...] produzir moldes, que após o tecido ter sido cortado e montado reproduzam o desenho e estejam de acordo com as medidas" [ARAÚJO, 1996, p. 92]. Após o desenvolvimento dos moldes, também é tarefa do modelista criar a gradação: moldes equivalentes ao modelo inicial, mas correspondentes aos diferentes tamanhos da tabela de medidas utilizada pela empresa.

Na fase da modelagem, os estudos antropométricos fornecem os dados que estão catalogados na tabela de medidas do corpo humano, utilizada como padrão, para concretizar desde o protótipo até a produção em série. [...] a ergonomia é utilizada nessa fase, pois, no processo de planificação do corpo humano é necessário prever as questões ligadas a sua estática e sua dinâmica [ROSA, 2011, p. 151]. 
$16^{\circ}$ USIHC - Congresso Internacional de Ergonomia e Usabilidade de Interfaces Humano Computador

Existem inúmeras metodologias empregadas no sentido de realizar a modelagem e a gradação, as que serão analisadas neste estudo são: Modelagem Plana, Moulage, e Modelagem em CAD. Cada uma destas será estudada mais profundamente na sequência.

As modelagens plana e em CAD, de certa forma, podem ser consideradas similares, pois ambas trabalham no sentido de pensar primeiramente os cortes de tecido em 2D, para que então, após costuradas as partes e constituída a roupa em 3D, se consigam os efeitos propostos na criação. Já a Moulage realiza o processo inverso, iniciando com a disposição do tecido sobre um manequim tridimensional, onde forma-se o primeiro protótipo da roupa. E posteriormente, através do refilamento das partes constituintes, se chega ao resultado dos moldes a serem cortados no tecido, invariavelmente, bidimensional.

\subsection{Modelagem Plana}

O procedimento padrão no desenvolvimento da modelagem plana inicia a partir das bases, "[...] conjuntos de moldes sem qualquer interesse estilístico mas com pormenores estruturais em locais clássicos ou tradicionais" [ARAÚJO, 1996 p. 95]. As variações de modelos são criadas sobre as bases já testadas e confirmadas quanto ao ajuste ergonômico de acordo com as especificações e tabelas de medidas determinadas pela empresa, e podem ser reutilizadas diversas vezes, o que confere agilidade, eficiência e consistência ao processo. Faz-se necessária a produção de modelagens base para diferentes partes do corpo e tipos de estruturação, por exemplo, base para a parte superior do corpo, com mangas nos modelos clássico e raglan; para a parte inferior do corpo sendo calças ou saias; base para vestidos, entre outras. São diferenciadas também as bases destinadas ao corte de tecidos planos e malhas.

Araújo [1996] afirma que a utilização de bases de modelagem bem desenvolvidas é um dos fatores que conferem qualidade ao produto final, uma vez que colabora com a padronização das medidas e proporções de tamanhos entre as peças de uma mesma marca ou linha de produtos. Outro ponto positivo seria a facilidade em efetuar a gradação quando as bases dispuserem as marcações específicas dos "pontos de gradação", especificando as marcas no plano cartesiano a partir do qual se planeja os aumentos e reduções de tamanhos. As margens de costura são geralmente adicionadas apenas ao final do processo, facilitando a manipulação das bases e a especificação da margem de acordo com o tipo de costura escolhido e tipo de tecido.

Porém, apesar do uso de bases promover certa agilidade ao processo, se faz necessária a confecção de peças piloto, pois

[...] por mais que um produto acabado apresente as medidas em conformidade com a tabela de referência de tamanhos, não se pode garantir que tenha dimensões adequadas. É preciso que essas medidas estejam distribuídas de forma a acomodar adequadamente as saliências e reentrâncias do corpo, o que só pode ser averiguado vestindo-se a peça [MENEZES; SOUZA, 2010, p. 4].

Uma sequência do desenvolvimento dos moldes é apresentada por Araújo [1996], algumas das principais etapas incluem: recepção e interpretação do desenho técnico, adaptação dos moldes base conforme o modelo, corte e costura da peça piloto, repetidos testes em manequins e modelos de prova, ajustes das medidas e possíveis falhas, implementação de modificações visando aumento na qualidade ergonômica e no aproveitamento do tecido, aprovação final e gradação para demais tamanhos.

Uma das principais deficiências da modelagem plana é a deterioração dos moldes de papel conforme seu uso repetitivo, "[...] cada vez que um molde é copiado, por muito cuidado que se tenha, há sempre a possibilidade de se introduzirem erros e irregularidades" [ARAÚJO, 1996, p. 102]. Após algumas cópias do traçado dos moldes, os erros mais recorrentes são arredondamento das
Realização:

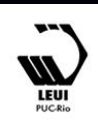

UNIVERSIDADE FEDERAL DE SANTA CATARINA
INSTITUTO FEDERAL

Santa Catarina

Câmpus Palhoça Bilíngue 
$16^{\circ}$ USIHC - Congresso Internacional de Ergonomia e Usabilidade de Interfaces Humano Computador

CINAHPA | 2017 - Congresso Internacional de Ambientes Hipermídia para Aprendizagem.

extremidades, perda da exatidão das marcações de pontos específicos, rasgos e cortes inesperados, riscos inadvertidos e rasuras que podem ser confundidas com marcas de corte ou pences.

\subsection{Moulage}

Moulage é uma palavra de origem francesa, sem sinônimo definido na língua portuguesa. Silveira [2011] explica que este termo deriva da palavra francesa moule, que significa forma ou "dar forma". Justamente, este método trabalha a partir da forma do corpo tridimensionalmente, podendo ser sobre um modelo vivo, ou em um manequim apropriado para a técnica.

Contrariamente a modelagem plana e a em CAD, na Moulage iniciam-se os trabalhos usando o tecido. Algumas marcas de posicionamento são feitas além de cortes para que a tela fique no tamanho apropriado, e então se dá início ao desenvolvimento do modelo alfinetando e prendendo partes do tecido. Dessa forma, o primeiro protótipo físico da roupa é construído bastante cedo na ordem de execução do processo, permitindo que erros sejam identificados e solucionados antes da construção da peça piloto.

Na construção de um modelo do vestuário com a técnica Moulage, as características físicas de peso e espessura dos tecidos ganham volumes e caimentos diversos quando sobrepostos ao corpo. Os tecidos comportam-se de maneiras diferentes de acordo com a tensão e inclinação com que são manipulados, produzindo efeitos muitas vezes inesperados [SILVEIRA, 2011, p.3].

Por causa da visualização prévia dos efeitos do tecido no modelo, a utilização deste método pode acarretar na melhora da qualidade do produto final, no aumento da produtividade uma vez que diminui o retrabalho e o uso de tecido desnecessário para testes futuros, e inclusive oferece a possibilidade de que o estilista descubra novas possibilidades não pensadas anteriormente e efetue melhorias no resultado da criação.

Pode-se afirmar que devido à permanente visualização da peça durante a sua construção, a avaliação acaba acontecendo de forma contínua ao longo do processo [MENEZES; SOUZA, 2010, p. 3-4].

Outras vantagens da utilização da Moulage se referem a "adequação dimensional e vestibilidade do produto, bem como no consumo de matéria prima e nas soluções previstas para a montagem das peças" [MENEZES; SOUZA, 2010, p. 3-4].

Depois de aprovado o modelo, no processo de refilamento, as partes da tela são retiradas do manequim, passadas a ferro e transferidas ao papel de molde para que possam ser graduadas e cortadas no tecido final.

\subsection{Modelagem em CAD}

A utilização de tecnologias digitais para desenvolver modelagens é um recurso relativamente novo e ainda pouco acessível, principalmente para as empresas brasileiras. Atualmente existem grandes empresas nacionais que produzem softwares em português e maquinário para a implementação de $\mathrm{CAD}$ em diversos segmentos de indústrias têxteis, o que colabora com a evolução do processo produtivo da indústria nacional neste sentido. $\mathrm{O}$ software utilizado na presente análise é o Audaces Moldes, desenvolvido pela Audaces, empresa de Florianópolis - SC.

A modelagem desenvolvida em CAD pode ser diretamente comparada com a modelagem plana em alguns aspectos, principalmente em relação à maneira de desenhar as bases e moldes, pois a sequência operacional e a ordem de atividades são muito similares. Neste caso, o trabalho também inicia a partir de uma tabela de medidas determinada pela empresa, são desenvolvidas bases de trabalho digitais a partir das quais os moldes são criados de acordo com cada novo modelo de roupa aprovada pelo estilista e, após a realização de testes para verificar e ajustar a precisão ergonômica do produto é realizada a gradação para outros tamanhos estabelecidos. As principais 
diferenças entre as duas metodologias

correspondem à tecnologia e ao suporte utilizados.

Grosso modo, pode-se dizer que a modelagem plana e a em CAD realizam as mesmas tarefas, utilizando tecnologias distintas. Sendo que a segunda [...] segue os mesmos princípios de se modelar a mão, a correspondência com a forma manual torna mais fácil a associação do traçado com a ferramenta adequada [CASAGRANDE, 2008, P. 41]. A modelagem em CAD, ainda, como é feita em computadores, dispõe de todos os benefícios que esta ferramenta apresenta além das vantagens do acesso à internet.

A possibilidade de armazenar individualmente cada molde na memória do computador permite a utilização de um sistema de gradação e risco computadorizado, para construir uma biblioteca de blocos base e moldes individuais que podem ser combinados de forma criativa na produção de novos estilos [ARAÚJO, 1996, p. 137].

Experimentar novos traçados, recortes, localização de pences e pregas combinações entre peças, entre outras, são atividades realizadas muito mais rapidamente no CAD do que na modelagem feita à mão. A modelagem computadorizada ainda minimiza acidentes que podem comprometer a estrutura do molde em papel e, assim, o retrabalho, pois não apresenta a necessidade de riscar a lápis, apagar, dobrar, vincar, rasgar ou cortar o papel.

O computador de forma alguma substitui a habilidade e talento do modelista, mas ajuda-o a aumentar a sua produtividade e permite-lhe que se concentre mais nos aspectos criativos e menos nos aspectos rotineiros [ARAÚJO, 1996, p. 138].

Apesar das vantagens, alguns profissionais ainda optam por fazer uso misto das metodologias, frequentemente criando modelagens com a modelagem plana ou a Moulage, e então as digitalizando para que ajustes, correções, gradações e riscos sejam feitos virtualmente. Casagrande [2008] afirma que caso o profissional não disponha de suficientes prática e habilidade no sistema virtual, suas vantagens em relação à $16^{\circ}$ Ergodesign - Congresso Internacional de Ergonomia e Usabilidade de Interfaces Humano Tecnológica: Produto, Informações Ambientes Construídos e Transporte

$16^{\circ}$ USIHC - Congresso Internacional de Ergonomia e Usabilidade de Interfaces Humano Computador

CINAHPA | 2017 - Congresso Internacional de Ambientes Hipermídia para Aprendizagem. agilidade só se aplicam nas tarefas de risco e gradação. Sendo assim, nestes caso se pode afirmar que a utilização paralela entre a modelagem plana ou Moulage e a em CAD possui aspectos interessantes.

\section{Usabilidade}

A Organização Internacional de Normalização (ISO) define usabilidade como" [...] a eficácia, eficiência e satisfação com que usuários específicos podem atingir seus objetivos em determinados ambientes".( ISO DIS 9241-11, apud JORDAN,2001, p. 5). A usabilidade é, portanto, de acordo com Jordan (2001) uma propriedade da interação entre um produto, um usuário e a tarefa que o indivíduo está tentando completar. Para o autor (2001), a usabilidade não é apenas importante em relação aos produtos de consumo, da mesma forma, pode ter implicações importantes para a produtividade em ambientes de produção industrial e contexto profissionais.

Existem características básicas que favorecem a usabilidade de um sistema, estas características respeitam princípios, critérios ou heurísticas propostas por diversos autores. Neste artigo enfocou-se no conjunto de heurísticas e princípios propostos por Nielsen. Sendo assim, o autor divide a usabilidade em cinco critérios básicos como apresentado no diagrama abaixo;

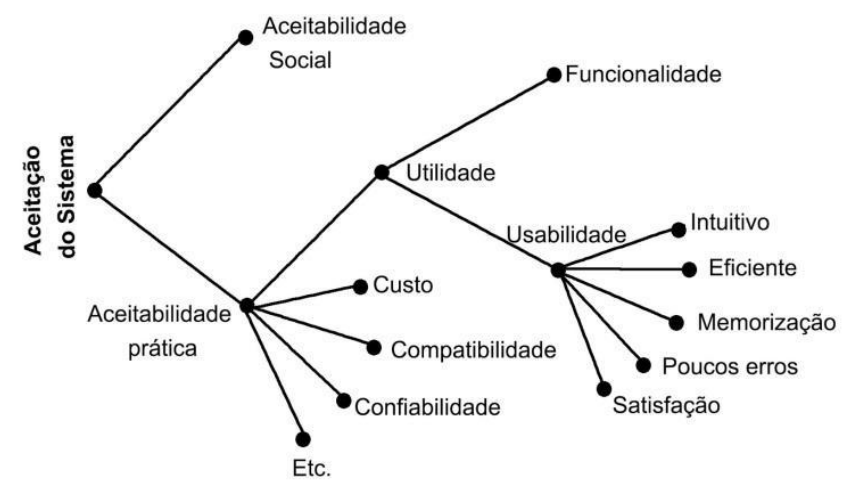

Diagrama 1. Modelo dos atributos de aceitabilidade do sistema.
Realização:

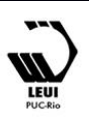

UNIVERSIDADE FEDERAL DE SANTA CATARINA 
$16^{\circ}$ USIHC - Congresso Internacional de Ergonomia e Usabilidade de Interfaces Humano Computador

Fonte: Nielsen [1993, p. 25] adaptado pelas autoras [2017].

É importante perceber que a usabilidade não é composta por uma única propriedade, e sim por ao menos estes cinco atributos propostos por Nielsen [1993]. A seguir um breve descrição destes;

- Intuitivo: O sistema deve ser fácil de aprender para que o usuário possa rapidamente começar a trabalhar com o sistema.

- Eficiência: O sistema deve ser eficiente de usar, de modo que uma vez que o usuário aprendeu o sistema, é possível conseguir um elevado nível de produtividade.

- Memorabilidade: O sistema deve ser fácil de lembrar, de modo que o usuário possa retornar ao sistema após algum período de não tê-lo usado, sem ter que aprender tudo novamente.

- Erros: O sistema deve ter uma baixa taxa de erro, de modo que os usuários façam poucos erros durante o uso do sistema, e de modo que se eles fizerem erros estes possam facilmente desfazê-lo.

- Agradável: O sistema deve ser agradável de usar.

Estes princípios podem ser usados para explicar uma proporção muito grande dos problemas observados em projetos de interfaces de usuário. Geralmente os problemas de usabilidade ocorrem durante a interação, atrapalhando o usuário na realização de sua tarefa, e consequentemente na perda de tempo, perda de dados, retrabalho, repetição, entre outros prejuízos. Deste modo é de extrema importância a avaliação da usabilidade, pois estas diagnosticam os problemas ou as barreiras que os usuários provavelmente encontrarão durante a interação.

Conforme Cybis, Betiol e Faust [2007] a origem do problema está na ergonomia da interface, ou seja, para a verificação da usabilidade é necessário realizar um diagnóstico dos aspectos ergonômicos envolvidos. Estas inspeções podem ser feitas através de avaliações heurísticas, visto que, "uma avaliação heurística representa um julgamento de valor sobre qualidades ergonômicas das interfaces" [CYBIS, BETIOL, FAUST, 2007, p183].

\subsection{As Heurísticas de Nielsen}

Nielsen avalia a usabilidade sob dez heurísticas, estas listam os princípios a serem seguidos no projeto de desenvolvimento de uma interface com o usuário. Em qualquer projeto, devem ser utilizados vários níveis de diretrizes: diretrizes gerais aplicáveis a todas as interfaces de usuário, e diretrizes específicas da categoria para o tipo de sistema que está sendo desenvolvido [Nielsen, 1993]. Normalmente as diretrizes de usabilidade têm na ordem de mil regras a seguir e, portanto, são vistas como intimidadoras pelos designers. No entanto, Nielsen as reduz a um conjunto de 10 heurísticas mais amplas, facilitando a compreensão e aplicação destas nos projetos. Estas são:

1. Diálogo simples e natural: Os diálogos não devem conter informações irrelevantes ou raramente necessárias. Estas informações irrelevantes diminuem a visibilidade das informações relevantes. Todas as informações devem aparecer em uma ordem natural e lógica.

2. Falar a linguagem dos usuários: O diálogo deve ser expresso claramente em palavras, frases e conceitos familiares ao usuário, em vez de em termos específicos e complexos do sistema.

3. Minimizar a sobrecarga de memória dos usuários: O usuário não deve ter que se lembrar de informações de uma parte do diálogo para outra. As instruções de utilização do sistema devem ser visíveis ou facilmente recuperáveis sempre que
Realização:

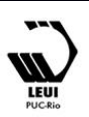



Interfaces Humano Tecnológica: Produto, Informações Ambientes Construídos e Transporte

$16^{\circ}$ USIHC - Congresso Internacional de Ergonomia e Usabilidade de Interfaces Humano Computador

CINAHPA | 2017 - Congresso Internacional de Ambientes Hipermídia para Aprendizagem.

adequado.

4. Consistência e padrões: A mesma informação deve ser apresentada na mesma localização de modo a facilitar o reconhecimento pelo usuário.

5. Feedback: O sistema deve sempre manter os usuários informados sobre o que está acontecendo, dentro de um prazo razoável.

6. Evidenciar as saídas: O sistema deve fornecer uma "saída de emergência" claramente marcada para deixar o estado indesejado e voltar ao estado anterior.

7. Atalhos: Tornam uma ação frequente mais rápida.

8. Mensagens de erro: Estas devem ser expressas em linguagem simples (sem códigos), indicar com precisão o problema e sugerir uma solução.

9. Prevenir erros: Melhor do que boas mensagens de erro é um sistema que impede que um problema ocorra em primeiro lugar.

10. Ajuda e documentação das funcionalidades: Informações de ajuda e documentação do sistema devem ser fáceis de pesquisar, com ênfase na tarefa do usuário, listar etapas concretas a serem realizadas e não ser muito extensas.

A avaliação heurística não fornece uma maneira sistemática de gerar correções para os problemas de usabilidade ou uma forma de avaliar a qualidade provável de qualquer redesign. No entanto, como a avaliação heurística visa explicar cada problema de usabilidade observado com referência aos princípios de usabilidade estabelecidos, será muitas vezes bastante fácil gerar uma revisão do projeto de acordo com informações recolhidas. Além disso, muitos problemas de usabilidade têm correções bastante óbvias uma vez identificados.

\section{Heurísticas de Nielsen aplicáveis aos métodos de modelagem}

De acordo com os autores Cybis, Betiol e Faust (2007) usabilidade não é uma propriedade intrínseca de um sistema, mas depende das relações entre usuário, interface, tarefa e ambiente. Sendo assim, em toda avaliação de usabilidade é necessário levar em conta a interferência destes fatores. Deste modo, a comparação conduzida neste artigo foi realizada partindo do ponto de vista de um usuário experiente com a tarefa de desenvolvimento de modelagem do vestuário e realizada em um ambiente de trabalho.

Estabelecidos estes parâmetros, foi realizado a comparação entre três métodos de modelagem do vestuário, a partir do conjunto de heurísticas definidas por Nielsen [1993].

Nas tabelas a seguir encontram-se as classificações das metodologias de modelagem apresentadas neste estudo de acordo com cada uma das heurísticas de Nielsen. De forma a simplificar a visualização do conteúdo, instituiu-se um padrão numérico para substituir o nome das heurísticas, de acordo com a sequência: 1: Diálogo simples e natural; 2: Falar a linguagem do usuário; 3: Minimizar a sobrecarga de memória; 4 :

Consistência e padrões; 5: Feedback; 6: Evidenciar as saídas; 7: Fornecer atalhos; 8: Mensagens de erro; 9: Prevenir erros; 10: Fornecer ajuda e documentação das funcionalidades.

\begin{tabular}{l|l} 
Heurística & Modelagem Plana \\
\hline 1 & Pouco texto, boa representação gráfica \\
\hline 2 & Mistura entre termos coloquiais e técnicos \\
\hline 3 & $\begin{array}{l}\text { Não, o profissional necessita decorar a sequência de } \\
\text { tarefas }\end{array}$ \\
\hline 4 & Apresenta \\
\hline 5 & Não apresenta \\
& Não aplica
\end{tabular}

Realização:

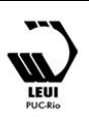



Interfaces Humano Tecnológica: Produto, Informações Ambientes Construídos e Transporte

$16^{\circ}$ USIHC - Congresso Internacional de Ergonomia e Usabilidade de Interfaces Humano Computador

CINAHPA | 2017 - Congresso Internacional de Ambientes Hipermídia para Aprendizagem.

\begin{tabular}{l|l}
7 & $\begin{array}{l}\text { Permite que cada usuário desenvolva seus próprios } \\
\text { atalhos }\end{array}$ \\
\hline 8 & Nulo \\
\hline 9 & Não previne \\
\hline 10 & Não, por ser um método de pouca interação
\end{tabular}

Tabela1. Comparação do método de modelagem plana mediante as heurística de Nielsen.

Na modelagem plana, a linguagem gráfica compõe a maior parte do texto presente, que é construído na medida em que o profissional desenha manualmente traços geométricos em um plano cartesiano. É o usuário quem estabelece o ritmo e a velocidade do desenvolvimento do método, com flexibilidade para criar sua própria linguagem.

A modelagem plana é a que mais exerce sobrecarga de memória, pois não apresenta um limite definido entre a execução de uma e outra tarefa, fazendo com que a aplicação correta do método depende exclusivamente da memória do usuário. Este pode optar por fazer uso de cadernos ou apostilas para consulta durante o trabalho, para obter um apoio quanto às diretrizes de tarefas, mas esta é uma escolha pessoal e alheia ao método. Nesse ponto, pode-se ressaltar que o método não fornece ajuda ou documentação de funcionalidades, o que também pode ser resolvido através de consulta. Um fator de auxílio neste sentido é a consistência de padrões que possibilita decorar o passo-a-passo após algum tempo de prática.

Não existe qualquer tipo de fornecimento de informações sobre o que está sendo realizado, obrigando o próprio usuário a conferir sistematicamente cada atividade pontual em comparação com o todo do trabalho. Da mesma forma, não ocorre a oferta de saídas para se retornar a um estágio anterior, é necessário que o usuário apague algum traço riscado, ou remende uma parte do papel cortado, por exemplo.
Por ser um método de execução individual, permite que cada profissional trabalhe com as ferramentas da maneira como preferir, desenvolvendo seus próprios macetes e atalhos. Porém, não existem mensagens de erro e tão pouco um sistema de prevenção de erros, estes devem ser reconhecidos exclusivamente através de análise atenta por parte do usuário.

\begin{tabular}{c|l} 
Heurística & Moulage \\
\hline 1 & Texto gráfico \\
\hline 2 & Sim \\
\hline 3 & $\begin{array}{l}\text { Sim, porque o método permite a visualização do } \\
\text { trabalho como um todo, simplificando a percepção da } \\
\text { sequência de tarefas }\end{array}$ \\
\hline 4 & $\begin{array}{l}\text { Apresenta com certa flexibilidade } \\
\text { Apresenta, porque mantém o usuário informado através } \\
\text { da visualização da tarefa }\end{array}$ \\
\hline 6 & Não se aplica \\
\hline 7 & $\begin{array}{l}\text { É um método que ajuda na visualização do erro antes } \\
\text { da conclusão da tarefa }\end{array}$ \\
\hline 9 & Não fornece \\
\hline 6 & Colabora na percepção da existência do erro \\
\hline
\end{tabular}

Tabela 2. Comparação dos métodos de Moulage mediante as heurística de Nielsen.

A Moulage possui ainda menos texto que a modelagem plana, mesclando algumas marcações geométricas com o ato do posicionamento do tecido sobre o manequim. Assim, a linguagem estabelecida pelo usuário é puramente visual e tátil. Pelo fato de o produto final da aplicação do método ser o primeiro protótipo finalizado da roupa, considera-se que a carga de memória necessária no processo não seja tão grande, uma vez que é possível a visualização do todo do processo na medida em que cada parte é executada. Esta fácil visualização do todo e de possíveis
Realização:

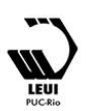

UNIVERSIDADE FEDERAL DE SANTA CATARINA 

Interfaces Humano Tecnológica: Produto, Informações Ambientes Construídos e Transporte

$16^{\circ}$ USIHC - Congresso Internacional de Ergonomia e Usabilidade de Interfaces Humano Computador

CINAHPA | 2017 - Congresso Internacional de Ambientes Hipermídia para Aprendizagem.

pontos de geração de problemas, indica que este método apresenta certo nível de feedback.

Em relação à consistência e padrões, este método os apresenta apenas de certo modo, pois tarefas podem ser incluídas ou suprimidas ao longo do processo. Existe uma sequência operacional, mas esta pode variar de acordo com as escolhas e preferências de cada profissional, e também conforme as particularidades de cada modelo. Ainda em relação a padrões, a Moulage é a metodologia que dispõe de maior flexibilidade na localização onde a informação é apresentada, pois apresenta apenas pequenas indicações para não sobrecarregar a memória.

De forma similar a modelagem plana, a Moulage também não apresenta evidências de saída ou atalhos. Pelo contrário, é necessário apagar ou sinalizar traços errados, e costurar partes do tecido quando cortado por acidente, em caso de possíveis erros. Não existem também mensagens de erro, mas nesse método a percepção de problemas se dá de forma mais clara, a visualização do processo como um todo permite a identificação de falhas e sua solução antes da conclusão das tarefas.

Por si só, a Moulage não é um método que oferece ajuda ou documentação das funcionalidades. Porém, os profissionais podem fazer uso de instrumentos de consulta à parte do método, como utilizar livros, cadernos e apostilas, entre outros.

\begin{tabular}{c|l} 
Heurística & Modelagem em CAD (Audaces) \\
\hline 1 & $\begin{array}{l}\text { Diálogo simples; uso de ícones para identificação das } \\
\text { tarefas. }\end{array}$ \\
\hline 2 & Utiliza termos técnicos de fácil compreensão \\
\hline 3 & Minimiza \\
\hline 4 & Apresenta \\
\hline 5 & Em determinadas ações \\
\hline 6 & Apresenta
\end{tabular}

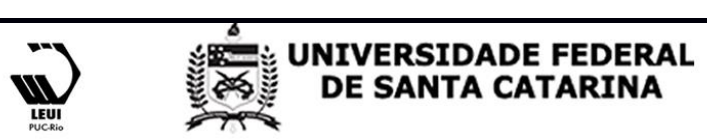

\begin{tabular}{l|l}
7 & Fornece tabela de atalhos \\
\hline 8 & $\begin{array}{l}\text { Não convida o usuário a fazer conferência ou } \\
\text { correções }\end{array}$ \\
\hline 9 & Previne alguns erros \\
\hline 10 & $\begin{array}{l}\text { Permite a consulta rápida das funcionalidades e acesso } \\
\text { a manual digital }\end{array}$
\end{tabular}

Tabela 3. Comparação do método de modelagem em CAD mediante as heurística de Nielsen.

A linguagem e o diálogo no método de modelagem com o uso de CAD são bastante familiares ao usuário, pois, além de fazer uso de termos técnicos com os quais ele já está habituado, são empregados diversos ícones que remetem a ferramentas utilizadas na modelagem plana manual, facilitando a associação por parte do usuário. Pode-se dizer que o CAD também suprime as informações pouco importantes. Com o uso de menus e agrupamento de ferramentas semelhantes, aparecem na tela apenas as funcionalidades usadas naquele momento, podendo ser substituídas conforme se avança na sequência operacional.

Este método é o único que oferece uma minimização real da carga de memória do usuário, pois o CAD mantém a disposição um manual digital com instruções de utilização do sistema, este recurso ainda oferece ajuda e documentação de funcionalidades. Também, pelo fato de a ferramenta utilizada ser o computador, existe a facilidade do acesso à Internet de forma simples e rápida, permitindo a busca por tutoriais e informações complementares on-line.

Uma forte característica do CAD é a consistência de padrões. As ferramentas e funções utilizadas se localizam sempre no mesmo espaço da tela, e o uso se dá seguindo uma sequência operacional definida e repetitiva. Neste ponto, o sistema oferece ainda a personalização da localização dos ícones, escolha das cores de fundo e do traço do desenho, além de permitir que o usuário crie atalhos personalizados de acesso às ferramentas. Ainda em relação aos padrões, pode acontecer que em processos de
Realização: puckio 
$16^{\circ}$ USIHC - Congresso Internacional de Ergonomia e Usabilidade de Interfaces Humano Computador

atualizações o software sofra algumas mudanças em relação à localização e disposição iconográfica de suas funcionalidades.

O sistema oferece feedbacks em determinadas ações, e evidencia saídas. No caso da execução de traços ou formação de moldes errados, ou

simplesmente para visualizar o passo anterior e, em seguida, voltar ao estágio atual, existem as funções de "desfazer" e "refazer", que permitem a rápida correção de erros e ajustes. Para se executar a tarefa de extrair um molde, por exemplo, é necessário que a base esteja com todos os seus vértices bem fechados, sem espaço entre um ponto e outro. Neste caso, se os ângulos não estiverem de acordo, e é solicitada a extração de um molde, o CAD disponibiliza uma mensagem avisando do problema, porém, sem indicar o ponto onde o erro ocorreu.

Em relação à sequência operacional do método e a execução das tarefas, o sistema não oferece prevenção do erro, exigindo experiência do usuário e habilidade neste sentido. Porém, nota-se a presença de recursos típicos do meio digital, como o botão para fechar a janela ser vermelho com um " $X$ " e localizado no canto direito superior; o botão de salvar sem em formato de disquete, e surgir um questionamento quando se ordena o fechamento de uma janela contendo um trabalho ainda não salvo.

\section{Considerações Finais}

A usabilidade pode ser medida a partir de critérios ergonômicos, uma vez que esta se aplica a todos os aspectos de um sistema com o qual o homem pode interagir, de modo que estes estejam adaptados à maneira como o usuário pensa, comporta-se e realiza as tarefas. Um problema de usabilidade é observado quando um problema de ergonomia do sistema ocasiona a perda de tempo e compromete a qualidade da tarefa. Sendo assim, o intuito deste estudo foi verificar se há, de fato, problemas ergonômicos nos métodos de modelagem do vestuário.
Pode-se perceber, através da análise das tabelas vistas anteriormente, que dentre os métodos considerados neste estudo a modelagem plana é o que apresenta menos heurísticas: apenas quatro de dez. Estando ausentes: Minimizar a sobrecarga de memória; Feedback; Evidenciar as saídas; Mensagens de erro; Prevenir erros; e Fornecer ajuda e documentação das funcionalidades.

A Moulage apresenta seis das dez heurísticas, faltando: Evidenciar as saídas; Fornecer atalhos; e Fornecer ajuda e documentação das funcionalidades. $E$ a modelagem em CAD é a que obteve o melhor desempenho, apresentando nove do total de dez, ficando apenas com "Mensagens de erro" faltante.

Assim, pode-se concluir que a modelagem em CAD é o método que se apresenta de uma maneira mais completa em relação aos critérios das heurísticas, quando comparado diretamente com a modelagem plana e a Moulage. Porém, este resultado pode ser devido a que o método CAD é o único que se trata de uma interface computacional.

Levando em consideração que estes métodos de modelagem não são excludentes, e que muitas vezes o trabalho iniciado com um pode ser concluído com colaboração de outro, indica-se que a melhor forma de atingir a totalidade dos requisitos de usabilidade e ergonomia seja com o uso conjunto de dois ou mais métodos, de acordo com a preferência do profissional quanto à familiaridade e conforto em fazer uso de metodologias distintas. $\cdots$.

Os resultados trouxeram importante contribuição para a abordagem deste assunto, pouco explorado cientificamente. As heurísticas demonstraram ser uma boa ferramenta para a identificação de problemas de usabilidade nos métodos de modelagem, mesmo naqueles que não tinham uma interface computacional. Para pesquisas futuras sugere-se a realização de entrevistas com profissionais na área e a utilização de outros métodos de avaliação da usabilidade para se obter dados mais completos.
Realização:

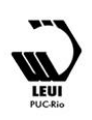

UNIVERSIDADE FEDERAL DE SANTA CATARINA 


\section{Referências Bibliográficas}

ARAÚJO, Mário de. Tecnologia do Vestuário. Lisboa: Fundação Calouste Gulbenkian, 1996.

\section{CASAGRANDE, Heide Gomes. CAD de} modelagem: Comparativo de eficiência entre processos manuais e computadorizados de interpretação e graduação de moldes. 2008. 49 f. TCC (Graduação) - Curso de Tecnologia em Produção de Vestuário, SENAI/CETICT, Rio de Janeiro, 2008. Disponível em:

$<$ https://pt.slideshare.net/heidegomes/comparativode-eficincia-entre-processos-manuais-ecomputadorizados-de-interpretao-e-graduao-demoldes>. Acesso em: 15 mar. 2017.

CYBIS, Walter; BETIOL, Adriana Holtz; FAUST, Richard. Ergonomia e usabilidade:

conhecimentos, métodos e aplicações. São Paulo:

Novatec editora, 2007.

IERVOLINO, Fernanda. 41 anos de estudos de modelagem do vestuários: uma proposta de aperfeiçoamento do ensino de modelagem através da usabilidade. 2014.91f. Dissertação (Mestrado), programa de pós-graduação em Design, Universidade do Estado de Santa Catarina, Florianópolis, 2014.

JORDAN, Patrick W. An introduction to usability. London: Taylor \& Francis, 1998. 120 p.

MENEZES, M. dos S.; SOUZA, P. de M. A Expressão Tridimensional nos Processos de Criação de Produtos de Moda. $9^{\circ}$ Congresso Brasileiro de Pesquisa e Desenvolvimento Em Design (Anais). São Paulo, 13 a 16 de out de 2010.

NIELSEN, Jakob. Usability Engineering.

London. Academic Press, 1993.

PAIVA, Rebeka Spindola de Almeida. Modelo para observação das etapas produtivas em empresas de confecção. 2010. 62 f. Dissertação (Mestrado) - Curso de Pós-graduação em Moda, Cultura de Moda e Arte, Universidade Federal de $16^{\circ}$ Ergodesign - Congresso Internacional de Ergonomia e Usabilidade de Interfaces Humano Tecnológica: Produto, Informações Ambientes Construídos e Transporte

$16^{\circ}$ USIHC - Congresso Internacional de Ergonomia e Usabilidade de Interfaces Humano Computador

CINAHPA | 2017 - Congresso Internacional de Ambientes Hipermídia para Aprendizagem.
Juiz de Fora, Juiz de Fora, 2010. Disponível em: < http://www.ufjf.br/posmoda/files/2010/09/Modelopara-observa\%C3\%A7\%C3\%A3o-das-etapasprodutivas-em-empresas-de-.pdf $>$. Acesso em: 18 ago. 2016.

ROSA, Lucas da. Vestuário industrializado: uso da ergonomia nas fases de gerência de produto, criação, modelagem e prototipagem. 2011. $175 \mathrm{f}$. Tese (Doutorado) - Curso de Design, PUC-Rio, Rio de Janeiro, 2011. Disponível em: $<$ http://www2.dbd.pucrio.br/pergamum/biblioteca/php/mostrateses.php?o pen $=1 \&$ arqtese=0721271_2011_Indice.html $>$. Acesso em: 09 mar. 2016.

SILVEIRA, Icléia. Modelagem tridimensional Moulage. Florianópolis: UDESC-CEART, 2011.
Realização:

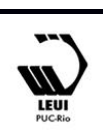

